\title{
The pulmonary vascular blood supply in the pulmonary atresia with ventricular septal defect and its implications in surgical treatment
}

\author{
O suprimento sangüíneo vascular pulmonar na atresia pulmonar com comunicação interventricular \\ e suas implicações no tratamento cirúrgico
}

\author{
Ulisses Alexandre CROTI ${ }^{1}$, Miguel Lorenzo BARBERO MARCIAL ${ }^{2}$, Carla TANAMATI ${ }^{2}$, Marcelo Biscegli \\ JATENE $^{2}$, Sergio Almeida de OLIVEIRA ${ }^{2}$
}

RBCCV 44205-617

\begin{abstract}
Objective: With base in the studies cineangiocardiography of pacients with pulmonary atresia (PA) with ventricular septal defect (VSD), to identify in the groups proposed by BARBERO MARCIAL, subgroups with similar morphological characteristics, to measure their central pulmonary arteries (CPA) and major aortopulmonary collateral arteries (MAPCA), thereby establishing their implications in surgical treatment.

Method: Sixty three patients were classified in groups A (15), B (40) and C (8) between january 1990 and june 2001. Patients with complete cineangiocardiograms prior to the first surgical intervention were included in this study, being calculated the pulmonary arterial index (PAI), the major aortopulmonary collateral arterial index (MAPCAI) and the total neopulmonary arterial index (TNPAI = PAI + MAPCAI). Surgical treatment was considered palliative (PT), definitively palliative (DPT) and definitive (DT).

Results: Nine subgroups were identified, A (A1 and A2), B (B1, B2, B3, B4 and B5) and C (C1 and C2). In group A, the PAI of patients for DT was higher than for PT patients $(p=0,0092)$. In group $B$, the TNPAI of DT patients was greater than for PT patients $(p=0,0959)$. In group $C$, the MAPCAI in
\end{abstract}

DPT patients was lower than in PT and DT patients. In the group A was not mortality, in the group B was of $17,5 \%$ and in the group $\mathrm{C}$ was of $12,5 \%$.

Conclusions: Among the groups A, B e C was possible to identifiy nine subgroups, the morphologic and morphometric characteristics allowed to suggest the surgical treatment in the patients of the group A had larger chance of TD, the group B of TP and the group C of TPD. The mortality presented larger correlation with the morphologic characteristics that with the morphometric.

Descriptors: Pulmonary atresia, surgery. Pulmonary atresia, physiopathology. Heart septal defects, ventricular, surgery. Heart defects, congenital, surgery.

\section{Resumo}

Objetivo: Com base nos estudos cineangiocardiográficos de pacientes portadores de atresia pulmonar (AP) com comunicação interventricular (CIV), identificar nos grupos propostos pela classificação de BARBERO MARCIAL, subgrupos com suprimento sangüíneo vascular pulmonar que apresentem características morfológicas semelhantes, mensurar suas artérias pulmonares centrais (AAPP), bem

Work performed in the Instituto do Coração of the Hospital das Clínicas of the Medical School of the University de São Paulo.

1 Hospital de Base of the Medical School of São José do Rio Preto.

2 Instituto do Coração of the Hospital das Clínicas of the Medical

School of the University de São Paulo.

Correspondence address: Ulisses Alexandre Croti.

Av. Brigadeiro Faria Lima, 5416, Sala 7.

São José do Rio Preto, SP.

CEP: 15090-000.

Telephone (Fax): (17) 210-5025.

E-mail: uacroti@cardiol.br 
como as artérias colaterais sistêmico-pulmonares (ACSP), procurando estabelecer as implicações no tratamento cirúrgico.

Método: Sessenta e três pacientes classificados em grupos A (15), B (40) e C (8) entre janeiro de 1990 e junho de 2001. Foram incluídos os pacientes com estudo cineangiocardiográfico completo e prévio à primeira intervenção cirúrgica, calculando-se o índice arterial pulmonar (IAAPP), índice arterial colateral sistêmicopulmonar (IACSP) e índice arterial neopulmonar total $($ IANPT = IAAPP + IACSP). O tratamento cirúrgico foi considerado paliativo (TP), paliativo definitivo (TPD) e definitivo (TD).

Resultados: Nove subgrupos foram identificados, A (A1 e A2), B (B1, B2, B3, B4 e B5) e C (C1 e C2). No grupo A, o IAAPP dos pacientes que chegaram ao TD foi maior que o dos

\section{INTRODUCTION}

Pulmonary atresia (PA) with ventricular septal defect (VSD) is defined as a group of cardiopulmonary malformations of coni-truncal origin, in which there is an interruption in the continuity of the lumen and absence of blood flow between the ventricles and the central pulmonary arteries (CPA). In a biventricular heart this presents with an orifice in the interventricular septum [1].

Commonly this is seen with a microdeletion of the long arm of chromosome 22 (q11.2), generally with nonconfluence of the CPA and the presence of major aortopulmonary collateral arteries (MAPCA) [2], giving a complex morphology and an unknown prognosis [3].

The fundamental key for surgical treatment is knowledge of the anomalies of pulmonary vascular blood supply. This can be very complex and with great anatomical variations, where the segments of the pulmonary lobes can be supplied by blood originating in the CPA and/or the MAPCA [4].

Utilizing cardiac cineangiographic studies it is possible to adequately identify the presence, size, existence of confluence and stenosis between the CPA. The origin, course and distribution of the MAPCA for the pulmonary segments should also be known, obtaining a complete and detailed map of the pulmonary vascular blood supply, fundamental in the adequate planning of a surgical strategy [5].

Barbero-Marcial \& Jatene [6] with the aim of facilitating surgical treatment, classified the pulmonary blood supply of patients suffering from PA with VSD in three distinct groups: A, B and C (Figure 1). com TP (p=0,0092). No grupo $B$, o IANPT dos pacientes em TD foi maior que os em TP (p=0,0959). No grupo C, o IACSP dos pacientes em TPD foi menor que os TP e TD. No grupo $A$ não houve mortalidade, no grupo $B$ foi de $17,5 \%$ e no grupo $C$ de $12,5 \%$.

Conclusões: Dentre os grupos A, B e C foi possível identificar nove subgrupos, sendo que as características morfológicas e morfométricas permitiram sugerir que o tratamento cirúrgico nos pacientes do grupo A têm maior chance de TD, nos do grupo B de TP e nos do grupo C de TPD. A mortalidade apresentou maior correlação com as características morfológicas que com as morfométricas.

Descritores: Atresia pulmonar, cirurgia. Atresia pulmonar, fisiopatologia. Defeitos do septo interventricular, cirurgia. Cardiopatias congênitas, cirurgia.
Type A

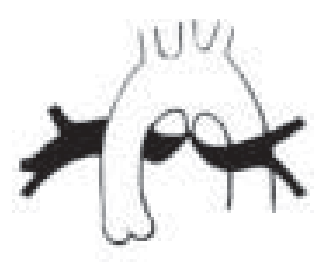

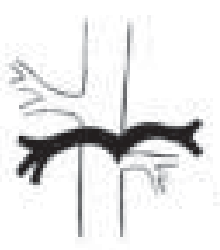

Type B

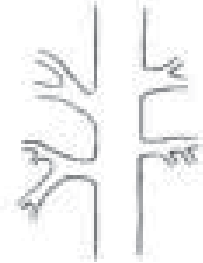

Type C
Fig. 1 - Barbero-Marcial classification for the pulmonary vascular blood supply in pulmonary atresia with interventricular communication [5].

In group A all the pulmonary segments are supplied by CPA and the surgical objective consists of assuring the presence of the CPA, with a size, distribution and pulmonary resistance that permits a complete correction.

In group B, some pulmonary segments are supplied by CPA, while others are supplied by MAPCA and the objective is to unify the pulmonary circulation, anastomosing the MAPCA to the CPA and stimulating the development of an adequate pulmonary blood supply.

In group $\mathrm{C}$, all the pulmonary segments are supplied by MAPCA, the CPA are absent and the objective is also to unify the pulmonary circulation, anastomosing the MAPCA with each other and/or lobar arteries of the hilum pulmonis when existent.

In 1984, Nakata et al. [8] proposed a method for the calculation of the area of CPA, which allows calculation of the pulmonary arterial index (PAI) and which can be applied to patients with blood supplies from a distinct origin (Group A).

Similarly, Reddy et al. [9] calculated the areas of MAPCA, obtaining the major aortopulmonary collateral arterial index 
(MAPCAI) and with this the total neo-pulmonary arterial index (TNPAI $=$ PAI + MAPCAI).

Calculation of these indices, that is, PAI for Group A, TNPAI for Group B and MAPCAI for Group C, are measurements that can be added to the morphological characteristics observed in the Barbero-Marcial classification to better direct surgical procedures.

Thus, with basis in the analysis of cine angiocardiograms of patients suffering from PA with VSD, the present study aims at identifying within the groups proposed by the Barbero-Marcial classification, subgroups with pulmonary vascular blood supplies that present similar morphological characteristics, to assess their CPA and MAPCA, to attempt to establish implications involved in surgical treatment.

\section{METHOD}

Between January 1990 and June 2001, 63 patients diagnosed as PA with VSD who were submitted to some type of surgical procedure at the Instituto do Coração do Hospital das Clínicas of the Medical School of the University of São Paulo were studied.

The patients were divided into groups according to the Barbero-Marcial classification [10].

Thirty (47.62\%) patients were male and $33(52.38 \%)$ were female.

The median age at the first cardiac cineangiographic study was 1.2 years (range 6 days to 21.6 years) and the median age of the first procedure was 1.6 years (from 9 days to 21.6 years).

\section{Inclusion criteria}

- Morphology of situs solitus and atrioventricular connections and concordant ventricular-arterial.

- Complete cardiac cineangiographic studies performed in the institution and obligatory before the first surgical intervention.

- The completion of patient records with the report of the first cineangiographic study and a description of all the operations performed.

\section{Exclusion criteria}

- Patients of whom it was not possible to obtain a cineangiographic study before the initial surgical treatment.

- Those of whom all the possible techniques to demonstrate the pulmonary vascular blood supply were not utilized, resulting in an incomplete examination.

- An incomplete cineangiographic study. The cineangiographic study was considered complete when it included: contrast injections in the ascending and descending aorta and the aortic arch, right and left ventricles, selective injections in the arterial canal, CPA, MAPCA, coronary arteries and retrograde venogram.

\section{Morphologic analysis}

In Group A, the caliber, presence of stenosis and confluence between the CPA were observed.

In Group B, which pulmonary lobes were supplied by the CPA and which were supplied by the MAPCA were identified.

In Group C, the caliber and the presence of stenosis in the MAPCA were investigated.

\section{Morphometric analysis}

The CAAS II software (cardiovascular angiography analysis system II) was utilized. The computer was connected to a Laser videodisc player LVA-7000 (JVC), Videocassette recorder SVO-9500 MD (SONY) and to a Tagarno cinevídeo camera, in such a way to allow the analysis of films recorded on the digital disc, VHS video and on $35 \mathrm{~mm}$ film.

The system was calibrated based on the diameter of the distal portion of the catheter.

The images selected for measurement were in the posteroanterior position and in ventricular systole.

After this calibration, the diameters of the CPA and MAPCA were measured. The CPA were measured immediately proximal to the root of the first lobar branch [8] and the MAPCA was measured distally to the point in which ideally the surgical unifocalization would be possible [9].

With the obtained measurements, the areas of the blood vessels were calculated.

Knowing the weight and height of the patients at the moment of the examination, the body surface was calculated utilizing Mosteller's formula [11].

Thus, it was possible to calculate the indices denominated as PAI (pulmonary arterial index) for Group A, MAPCAI (major aortopulmonary collateral artery index) for Group C and TNPAI (total neo-pulmonary artery index) for Group B.

\section{Surgical treatment}

The surgical treatment was considered palliative (PT), "definitive palliative" (DPT) or definitive (TD).

PT was defined for patients who were submitted to interventions without closing the VSD and with future perspectives of conclusion or not of the treatment. These patients were considered as being within the treatment process.

DPT was considered as those patients who were submitted to interventions without the closing the VSD and who did not present with further surgical options that would 
allow conclusion of treatment, with a right ventricular/central pulmonary artery connection and closure of the VSD.

DT when possible was by performing a right ventricular/ central pulmonary artery connection and the closure of the $\mathrm{VSD}$, allowing the reestablishment of the normal physiology.

\section{RESULTS}

Of the total of 63 patients, 15 (23.81\%) were in Group A, 40 (63.49\%) were in Group B and 8 (12.70\%) in Group C.

\section{Analysis of Group A}

The cardiac cineangiographic studies of all the patients of this group were submitted to morphometric analysis as can be seen in Table 1 .

Table 1. Morphometric characteristics of the pulmonary arteries, surgical procedures and stages of treatment in relation to the age and the body surface area in Group A.

\begin{tabular}{cccccc}
\hline Name & $\begin{array}{c}\text { Age } \\
(\mathbf{d a y s})\end{array}$ & $\begin{array}{c}\text { Body surface } \\
\text { area }\left(\mathbf{m}^{2}\right)\end{array}$ & $\begin{array}{c}\text { PAI } \\
\left(\mathbf{m m}^{2} / \mathbf{m}^{2}\right)\end{array}$ & $\mathbf{N}^{\circ}$. of procedures Treatment stage \\
\hline MCSS & 319 & 0.32 & 83.27 & 1 & DT \\
PLS & 1564 & 0.61 & 249.07 & 1 & DT \\
LGS & 485 & 0.38 & 177.60 & 1 & DT \\
RBS & 576 & 0.47 & 285.02 & 1 & DT \\
GNPM & 154 & 0.28 & 315.61 & 2 & DT \\
FSR & 315 & 0.35 & 408.96 & 1 & DT \\
TBB & 6 & 0.19 & 87.34 & 2 & DT \\
RB & 97 & 0.26 & 120.01 & 2 & DT \\
RAM & 167 & 0.28 & 132.31 & 1 & PT \\
VOS & 564 & 0.49 & 82.72 & 1 & PT \\
SIS & 379 & 0.40 & 139.58 & 2 & PT \\
GAC & 279 & 0.35 & 172.51 & 2 & DT \\
RKRF & 487 & 0.38 & 205.54 & 1 & DT \\
TCC & 508 & 0.52 & 244.15 & 1 & DT \\
DSO & 1944 & 0.76 & 391.74 & 2 & DT \\
\hline
\end{tabular}

PAI - pulmonary artery index; PT- palliative treatment; DTdefinitive treatment; $\mathrm{m}^{2}$ - square meters; $\mathrm{mm}^{2} / \mathrm{m}^{2}$ - square millimeters per square meters

Two subgroups were identified: A1 with 5 patients (33.33\%) and $\mathrm{A} 2$ with $10(6.67 \%)$ patients.

In subgroup A1, two patients presented normal CPA, two hypoplasia of the left pulmonary artery and one hypoplasia of the CPA. In all, the CPA were confluent and did not demonstrate stenosis.

Within subgroup A2, in eight patients the CPA were confluent, however presented with stenosis. In two, the CPA were not confluent. Of those with confluent CPA, four presented with stenosis in the left pulmonary artery and four in the CPA bilaterally.

Thus, the A1 subgroup was schematically represented by the patients who presented with normal-sized or hypoplastic confluent CPA without stenosis. The A2 subgroup, by patients who presented with non-confluent CPA or with stenosis (figure 2).

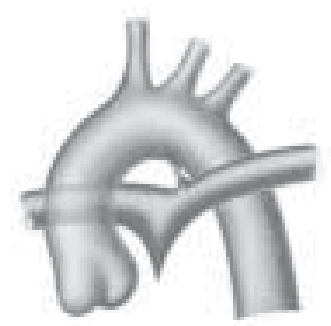

A1

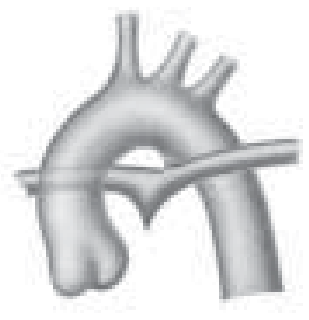

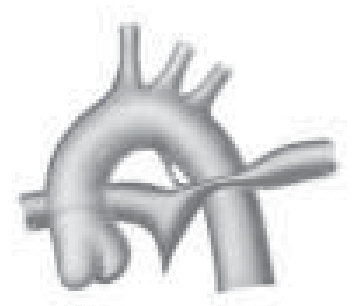

A2

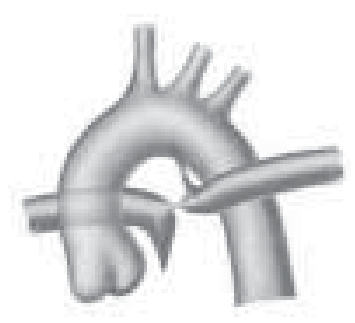

Fig. 2 - Schematic representation of subgroup A1 with normal or hypoplastic confluent pulmonary arteries and subgroup A2 with confluent and stenotic or non-confluent pulmonary arteries.

Notice that the proportion of patients from subgroup A1 who underwent DT was greater than those from subgroup A2.

There is no indication of a relationship between the number of procedures and the treatment stage for the patients in group A.

All the patients without stenosis or with stenosis in only one of the CPA achieved DT. On the other hand, only 50\% of the patients with stenosis in both CPA achieved DT.

In subgroup A2 there was a greater number of patients who required two procedures than in subgroup A1.

The mean of the PAI in the A1 and A2 subgroups was not different between the patients who underwent DT. However, the patients of the A2 subgroup who received PT presented with a lower mean PAI than the others ( $\mathrm{p}$-value $=0.0338$ ).

On average the PAI of the patients who received DT was significantly greater than the patients who underwent PT $(\mathrm{p}$-value $=0.0092)$.

There were no mortalities in group A.

\section{Analysis of group B}

The cardiac cineangiographic studies of all the patients of this group were submitted to morphometric analysis as can be seen in Table 2. 
Table 2. Morphometric characteristics of the pulmonary arteries and major aortopulmonary collateral arteries surgical procedures and treatment stages in relation to the age and the body surface area in Group B.

\begin{tabular}{|c|c|c|c|c|c|c|c|}
\hline Names & $\begin{array}{c}\begin{array}{c}\text { Age } \\
\text { (days) }\end{array} \\
\text { dat }\end{array}$ & $\begin{array}{c}\text { body } \\
\text { surface } \\
\text { area }\left(\mathbf{m}^{2}\right)\end{array}$ & $\begin{array}{c}\text { PAI } \\
\left(\mathrm{mm}^{2} / \mathrm{m}^{2}\right)\end{array}$ & $\begin{array}{l}\text { MAPCAI } \\
\left(\mathrm{mm}^{2} / \mathrm{m}^{2}\right)\end{array}$ & $\begin{array}{c}\text { TNPAI } \\
\left(\mathrm{mm}^{2} / \mathrm{m}^{2}\right)\end{array}$ & $\begin{array}{c}\mathbf{N}^{\circ} \text { of } \\
\text { procedures }\end{array}$ & $\begin{array}{c}\text { Treatment } \\
\text { stage }\end{array}$ \\
\hline MCP\# & 124 & 0.63 & 2.80 & 45.99 & 48.79 & 3 & DPT \\
\hline JPGL & 2287 & 0.81 & 87.07 & 69.58 & 156.65 & 2 & DT \\
\hline WLP & 404 & 0.47 & 15.46 & 80.69 & 96.15 & 1 & PT \\
\hline RMM & 350 & 0.48 & 19.65 & 82.09 & 101.74 & 2 & PT \\
\hline AAC & 7870 & 0.43 & 171.49 & 337.40 & 508.89 & 1 & DPT \\
\hline ASS & 427 & 0.43 & 14.61 & 56.15 & 70.76 & 1 & PT \\
\hline GRN\# & 635 & 0.40 & 42.80 & 131.88 & 174.69 & 1 & PT \\
\hline KDS & 886 & 0.54 & 108.70 & 99.12 & 207.82 & 1 & PT \\
\hline PRS & 265 & 0.39 & 59.71 & 129.06 & 188.77 & 1 & PT \\
\hline PSDS & 1696 & 0.70 & 164.08 & 144.35 & 308.43 & 1 & PT \\
\hline TSS & 357 & 0.34 & 68.49 & 155.30 & 223.79 & 2 & DT \\
\hline BFN\# & 250 & 0.36 & 54.15 & 182.12 & 236.27 & 2 & DT \\
\hline RDF & 102 & 0.26 & 59.27 & 152.33 & 211.60 & 2 & DT \\
\hline MRTT & 1658 & 0.63 & 32.14 & 36.10 & 68.24 & 1 & PT \\
\hline RRG & 390 & 0.41 & 559.19 & 317.60 & 876.78 & 2 & DT \\
\hline LSA & 324 & 0.39 & 203.07 & 247.35 & 450.42 & 1 & PT \\
\hline KLMN & 405 & 0.42 & 105.39 & 118.03 & 223.42 & 2 & DT \\
\hline CM & 125 & 0.38 & 130.31 & 113.51 & 243.82 & 1 & PT \\
\hline MALC & 2719 & 0.87 & 52.15 & 140.75 & 192.90 & 2 & PT \\
\hline GJB & 157 & 0.35 & 145.79 & 47.50 & 193.29 & 3 & PT \\
\hline JDCC\# & 352 & 0.41 & 243.06 & 79.17 & 322.23 & 1 & PT \\
\hline ARB\# & 314 & 0.41 & 199.62 & 210.33 & 409.95 & 2 & PT \\
\hline MSP & 3607 & 1.01 & 35.12 & 36.59 & 71.71 & 1 & PT \\
\hline BCIT & 893 & 0.45 & 77.14 & 73.48 & 150.62 & 1 & PT \\
\hline JDCS & 476 & 0.30 & 228.28 & 184.01 & 412.30 & 1 & DT \\
\hline FAT & 339 & 0.34 & 192.19 & 226.49 & 418.67 & 1 & PT \\
\hline MGDS & 240 & 0.38 & 10.02 & 139.36 & 149.39 & 1 & PT \\
\hline NMLS & 305 & 0.46 & 34.30 & 95.90 & 130.20 & 1 & PT \\
\hline CRN & 82 & 0.57 & 39.90 & 83.00 & 122.90 & 1 & PT \\
\hline MFS\# & 2196 & 0.74 & 61.98 & 45.45 & 107.43 & 2 & PT \\
\hline ARM & 1622 & 0.68 & 108.53 & 155.07 & 263.60 & 1 & PT \\
\hline DWG & 75 & 0.22 & 17.17 & 91.17 & 108.35 & 2 & PT \\
\hline BRAP & 1427 & 0.62 & 53.52 & 119.03 & 172.55 & 1 & PT \\
\hline ERS & 5246 & 1.37 & 24.26 & 40.13 & 64.40 & 1 & PT \\
\hline MGDS & 4436 & 1.34 & 91.35 & 37.15 & 128.50 & 1 & DT \\
\hline NOS & 1109 & 0.35 & 58.36 & 73.62 & 131.99 & 1 & PT \\
\hline LGK & 1288 & 0.58 & 178.12 & 114.53 & 292.65 & 1 & PT \\
\hline TMPS & 333 & 0.34 & 4.53 & 66.90 & 71.42 & 1 & PT \\
\hline TSS & 9 & 0.22 & 69.11 & 68.61 & 137.73 & 2 & PT \\
\hline LME\# & 2322 & 0.68 & 7.22 & 288.44 & 295.66 & 1 & PT \\
\hline
\end{tabular}

PAI - pulmonary artery index; MAPCAI- major aortopulmonary collateral artery index; TNPAI - total neo-pulmonary arterial index; PT- palliative treatment; TPD- definitive palliative treatment; TDdefinitive treatment; $\mathrm{m}^{2}$ - square meters; $\mathrm{mm}^{2} / \mathrm{m}^{2}$ - square millimeters per square meters; \#- deaths

Five subgroups were identified: B1 with $8(20 \%)$ patients, B2 with $4(10 \%)$ patients, B3 with $16(40 \%)$ patients, B4 with $4(10 \%)$ patients and B5 with $8(20 \%)$ patients.

In group B1, all the patients presented with CPA supplying the segments of the left upper and lower right lobes. In some patients the MAPCA were also present in these segments, however the CPA were predominant. All the other segments were irrigated by MAPCA (Figure 3).

In subgroup B2, all the patients presented with CPA supplying the segments of the upper right and left lower lobes. In some patients the MAPCA were also present in these segments, however the CPA were predominant. All the other segments were irrigated by the MAPCA (Figure 3).
In subgroup B3, all the patients presented with CPA supplying the segments of the left and right lower lobes or supplying the segments of one of the lower lobes and the majority of the lobes of the contralateral lung (Figure 3).

In subgroup B4, all the patients presented with CPA supplying the segments of the left and right upper lobes or supplying the segments of one of the upper lobes and the majority of the segments of the lobes of the contralateral lung (Figure 3).

In subgroup B5, the patients presented with a great diversity in the distribution of the CPA and MAPCA, with great difficulty to define the blood supply of the pulmonary segments.

Three patients presented with agenesis of the left pulmonary artery, two of the right pulmonary artery, two fistulae of the left coronary branch to the pulmonary branch and one had hypoplastic CPA.

In all these patients it was not possible to adequately identify which pulmonary segments were supplied by the CPA or MAPCA.

Thus, this subgroup consisted of a miscellaneous group of patients of group B (Figure 3).

There were more patients in subgroup B2 that received DT than in the other subgroups of group B, however without statistical significance.

The only patients who underwent DPT were from subgroup B1.

No patient who underwent three procedures achieved DT. The majority of the patients with DT were submitted to two procedures.

All patients with stenosis in at least one CPA received PT.

The presence of stenosis did not indicate any relationship with the stage of treatment of the patients.

The majority of the patients of subgroup B5 underwent only one procedure.

The number of patients who underwent one, two or three procedures in the $\mathrm{B} 1$ and $\mathrm{B} 3$ subgroups is very similar. The same can be said in respect to the B2 and B4 subgroups.

There were no statistical differences between the patients who underwent PT, DPT and DT in relation to the PAI, MAPCAI and TNPAI.

The greatest proportion of deaths was seen in the B1, B2 and B4 subgroups.

In the B1 subgroup there were $2(25 \%)$ mortalities, in B2 1 (25\%), in B3 $2(12.5 \%)$, in B4 1 (25\%) and in B5 1 (12.5\%). In all of group B there were 7 (17.5\%) deaths. 

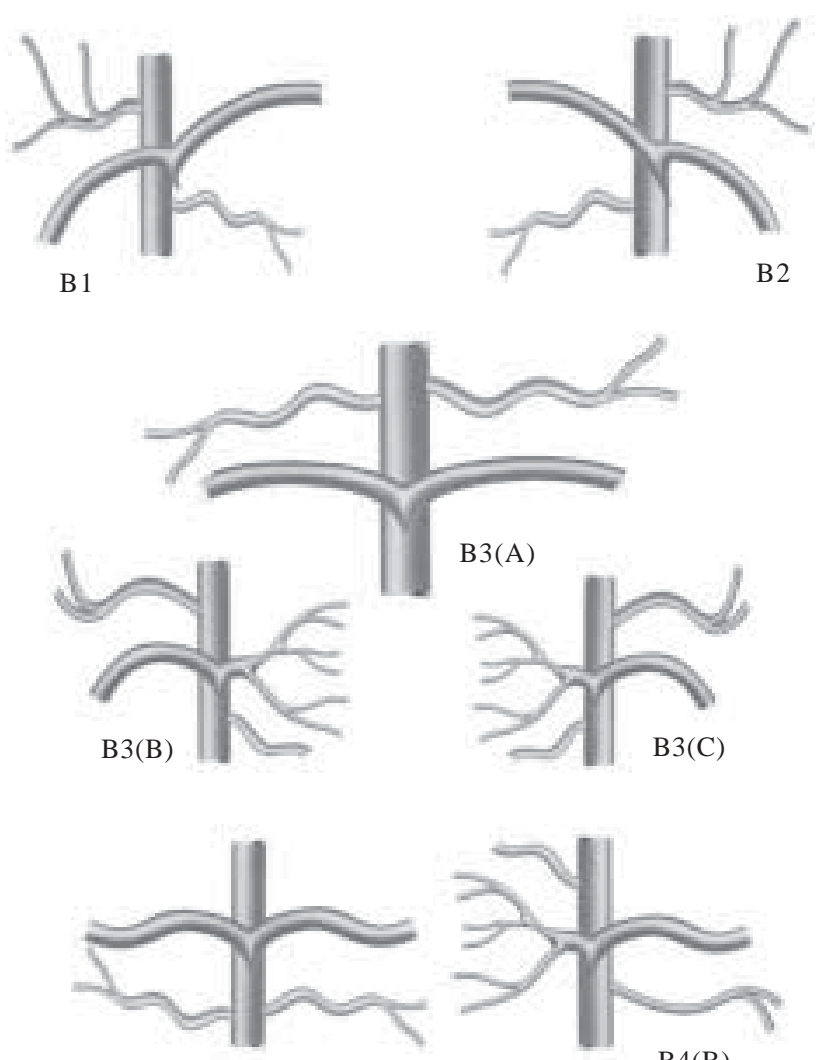

B4(A)
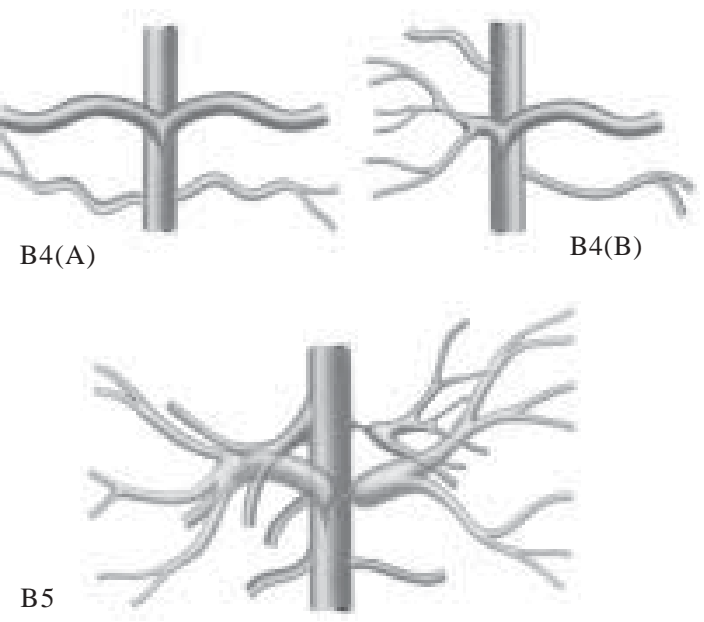

Fig 3. Schematic representation of the B1 subgroup with central pulmonary arteries supplying the left superior and right inferior lobes. The other lobes were irrigated by major aortopulmonary collateral arteries. The subgroup B2 with central pulmonary arteries supplying the upper right and left lower lobes. All the other lobes were irrigated by the major aortopulmonary collateral arteries. In subgroup B3 with central pulmonary arteries supplying the left and right lower lobes (A) or central pulmonary arteries supplying all the lobes of the left lung and the right upper lobe $(B)$. central pulmonary arteries supplying all the lobes of the right lung and the left upper lobe $(C)$. The other lobes being supplied by major aortopulmonary collateral arteries ( $A, B$ and $C$ ). In subgroup $B 4$ with central pulmonary arteries supplying the left and right upper lobes $(A)$. central pulmonary arteries supplying all the lobes of the left lung and the upper lobe of the right lung $(B)$. The other lobes being supplied by major aortopulmonary collateral arteries (A and B). In subgroup B5 with central pulmonary arteries and major aortopulmonary collateral arteries supplying lobes without possibility of exact definition.

\section{Analysis of group C}

The cardiac cineangiographic studies of all the patients of this group were submitted to morphometric analysis as can be seen in Table 3.

Table 3. Morphometric characteristics of the major aortopulmonary collateral arteries, surgical procedures and treatment stages in relation to the age and the body surface area in Group C.

\begin{tabular}{lccccc}
\hline Names & Age (days) & $\begin{array}{c}\text { Body surface area } \\
(\mathrm{m} 2)\end{array}$ & $\begin{array}{c}\text { MAPCAI } \\
\left(\mathrm{mm}^{2} / \mathrm{m}^{2}\right)\end{array}$ & $\begin{array}{c}\mathrm{N}^{\circ} \text { of } \\
\text { procedures }\end{array}$ & $\begin{array}{c}\text { Treatment } \\
\text { stage }\end{array}$ \\
\hline PRR & 326 & 0.36 & 113.25 & 2 & DPT \\
NRL & 75 & 0.32 & 165.16 & 1 & PT \\
RMM\# & 517 & 0.44 & 135.82 & 1 & PT \\
VKFG & 1131 & 0.56 & 531.57 & 2 & DT \\
CSS & 1363 & 0.46 & 108.54 & 1 & DPT \\
AAC & 4570 & 1.42 & 18.24 & 1 & DPT \\
NNGT & 456 & 0.48 & 90.40 & 2 & DPT \\
AFC & 761 & 0.51 & 91.73 & 1 & DPT \\
\hline
\end{tabular}

MAPCAI - major aortopulmonary collateral artery index; PTpalliative treatment; DPT - definitive palliative treatment; DTdefinitive treatment; $\mathrm{m}^{2}$ - square meters; $\mathrm{mm}^{2} / \mathrm{m}^{2}$ - square millimeters per square meter; \# - death

Two subgroups were identified: $\mathrm{C} 1$ with $5(65.5 \%)$ and C2 with $3(37.5 \%)$ patients.

In the five patients of subgroup $\mathrm{C} 1$, there was a total of five fine, eight medium and seven thick MAPCA.

In the 3 patients of subgroup $\mathrm{C} 2$ there was a total of two fine, six medium and three thick MAPCA.

Thus subgroup $\mathrm{C} 1$ was schematically represented by patients who had a greater number of medium or thick MAPCA and predominantly without stenosis and subgroup $\mathrm{C} 2$ was schematically represented by patients who presented with a greater number of medium or thin MAPCA and predominantly with local or segmental stenosis (Figure 4).

It is possible to observe that all the patients of subgroup C2 had outcomes of DPT, whilst in subgroup C1 only $40 \%$ achieved this stage.

There was no association among the numbers of MAPCA, the presence of stenosis and the treatment stages. Similarly, there was no statistical difference between group $\mathrm{C} 1$ and $\mathrm{C} 2$ in relation to the procedures performed.

Notable, the patients with DPT seem to present with a lower MAPCAI than the other patients.

In subgroup C1 there was 1 (20\%) death. In group C this mortality represented $12.5 \%$. 

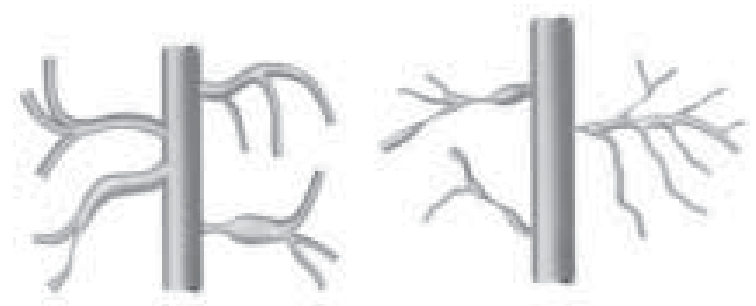

Fig. 4 - Schematic representation of subgroup C1 with thick and medium major aortopulmonary collateral arteries, without predominance of stenosis, supplying all the pulmon\&ry lobes and of subgroup C2 with medium and fine major aortopulmonary collateral arteries with a predominance of stenosis, supplying all the pulmonary lobes.

\section{Analysis among the groups}

An á error of $5 \%$ was considered acceptable. The parametric student-t test and the non-parametric KruskalWallis and Wilcoxon tests were used.

Correlations between groups A, B, C, PAI, TNPAI, MAPCA and the stages of treatment (table 4) were made.

Table 4. Correlation between the A, B and C groups, their indices and treatment stages.

\begin{tabular}{lccc|ccc}
\hline & \multirow{2}{*}{ PAI } & TNPAI & MAPCAI & definitive & palliative & palliative definitive \\
\hline Groups & mean \pm SD & mean \pm SD & mean \pm SD & $\mathbf{N}^{\circ}(\%)$ & $\mathbf{N}^{\circ}(\%)$ & $\mathbf{N}^{\circ}(\%)$ \\
A & $206.36 \pm 107.16$ & & $12(80 \%)$ & $3(20 \%)$ & $0(0 \%)$ \\
B & $95.75 \pm 101.16$ & $218.64 \pm 157.78$ & $122.88 \pm 76.97$ & $8(20 \%)$ & $30(75 \%)$ & $2(5 \%)$ \\
C & & & & & & \\
\hline
\end{tabular}

$\mathrm{N}^{\mathrm{o}}$ - number; SD - standard deviation; PAI - pulmonary arterial index; MAPCAI - major aortopulmonary collateral artery index; TNPAI- Total neo-pulmonary arterial index

There was no evidence of statistical differences among the indexes: PAI for group A, TNPAI for group B and MAPCAI for group $C$ ( $p$-value $=0.2625)$.

In group A, $80 \%$ of the patients achieved DT, in group B $75 \%$ achieved PT and in group C $62.5 \%$ achieved DPT.

The indices of the patients who died were lower that those who survived, however, the differences were not statistically significant. The total mortality rate was $12.7 \%$.

\section{COMMENTS}

Within group A, in the A1 subgroup the mean PAI was 222.11. This data is compatible with data found by Nakata et al. [8] who studied a group of patients with Fallot's tetrad and found a PAI of between 150 and $250 \mathrm{~mm}^{2} / \mathrm{m}^{2}$ in the majority of the cases and favorable results with indices greater than $200 \mathrm{~mm}^{2} / \mathrm{m}^{2}$. All the patients in this subgroup achieved DT, independently of the PAI, demonstrating that there was no correlation between this characteristic and the treatment. The morphological aspects of the CPA had a greater influence in the surgical conduct. In the A2 subgroup, eight patients presented with confluent CPA all of whom suffered stenosis of the left pulmonary artery near to the arterial canal. Of these, four also presented with stenosis of the right pulmonary artery and only one achieved DT, showing that the presence of stenosis in both the CPA is an important factor in relation to surgical correction [12]. The seriousness of this can be seen by the greater number of procedures and the smaller number of patients who achieve DT when compared with the A1 subgroup. The lack of confluence of the CPA was not a relevant factor for DT and survival, however it should be noted that this only included two patients and both of whom presented with mean PAI (244.15 and 391.74) different to those found by Nakata et al. [8]. In their group of patients who underwent the Rastelli 's surgery, all had a PAI of less than $200 \mathrm{~mm}^{2} / \mathrm{m}^{2}$ and died. The mean PAI of the patients who achieved DT was significantly greater than of the patients who achieved palliative treatment (p-value $=0.0092)$, demonstrating that the PAI can help in the surgical conduct.

In the B1 subgroup only one patient achieved DT and this presented with an PAI significantly greater than the MAPCAI, demonstrating that in these patients the presence of developed CPA is a factor of fundamental importance for the adequate surgical treatment [13]. In the B2 subgroup, two individuals achieved DT and two PT. There was no correlation with the TNPAI, which was higher than $200 \mathrm{~mm}^{2} /$ $\mathrm{m}^{2}$ in all patients [9]. Only one had a PAI greater than the MAPCAI and this one achieved PT, clearly showing that there was no relation between the morphometric and the morphologic characteristics for the definition of which patients would achieve DT. In the B3 subgroup, four patients achieved DT with mean TNPAI of $431.02 \mathrm{~mm}^{2} / \mathrm{m}^{2}$. One presented with a PAI less than the MAPCAI, however the TNPAI was $211.60 \mathrm{~mm}^{2} / \mathrm{m}^{2}$. The others presented with PAI significantly greater than the MAPCAI. This suggests than among the other patients who achieved PT (mean TNPAI of $233.45 \mathrm{~mm}^{2} / \mathrm{m}^{2}$ ), those who can have the PAI greater than the MAPCAI have a better chance of achieving DT, as was also observed by Carotti et al. [14]. In the B4 subgroup, the mean TNPAI was $150.57 \mathrm{~mm}^{2} / \mathrm{m}^{2}$, with PAI lower than their 
respective MAPCAI. The morphological characteristics were more important and significant for the choice of treatment. All the patients are in the treatment stage PT, and can develop to DPT or DT, but the morphometric characteristics are not favorable for DT [14]. In the B5 subgroup, only one patient achieved DT, with a single procedure. This patient had at least 14 pulmonary segments supplied by CPA and presented with a TNPAI of $128.50 \mathrm{~mm}^{2} / \mathrm{m}^{2}$ with a PAI greater than its MAPCAI. The other achieved PT, independently of their indices, showing that the morphologic characteristics are more important than the morphometric aspects in this subgroup.

The mean TNPAI of the patients who achieved DT in the B group was $308.66 \mathrm{~mm}^{2} / \mathrm{m}^{2}$, a fact that demonstrates that the obtained morphometric measurements are of extreme importance as long as the relationship between the PAI and MAPCAI is analyzed.

It is important to observe that there was no significant difference between the PAI and the MAPCAI for the patients who underwent DT. But, for the patients in the PT and DPT stages the MAPCAI was greater, demonstrating that when the MAPCA predominate there is a greater chance of PT.

Within group $\mathrm{C}$, in the $\mathrm{C} 1$ subgroup the mean MAPCAI of the patients with PT was 150.49 and those with DPT it was 110.90, suggesting that patients with MAPCA and reduced diameters present with a greater difficulty of treatment. In the $\mathrm{C} 2$ subgroup all the patients achieved DPT and the mean MAPCAI was 66.79, demonstrating that the fine MAPCA are of difficult surgical management. The mean MAPCAI of group $\mathrm{C}$ of the patients who achieved DPT was 84.43 , that is, less than $150 \mathrm{~mm}^{2} / \mathrm{m}^{2}$ and with a worse prognosis [14].

The mortality of disease in this subgroup of patients was $12.7 \%$ compatible with other published results [13, $15,16]$.

MACÉ et al. [16], analyzing patients submitted to unifocalization, experienced a mortality rate of $9.1 \%$ in group $\mathrm{B}$ and $25 \%$ in group C. In this study, a greater mortality rate was registered in group $\mathrm{C}$ than in group $\mathrm{B}$, different to the result in our study. This fact might be explained by the small number of patients in group $\mathrm{C}$, as these are more seriously sick patients who were submitted to more difficult surgical therapies. The mean TNPAI of the patients who died was 227.86 and for those who survived it was 216.68 showing that the morphometric characteristics are less important than the morphological aspects in the surgical treatment.

In conclusion, adequate morphological knowledge of this severe congenital heart disease is more important than morphometric measurements which can be obtained, as diverse factors should be considered for guidance in the surgical treatment and evaluation of risk of mortality.

\section{CONCLUSIONS}

Among the Barbero-Marcial classification groups, it was possible to identify nine subgroups of patients: $\mathrm{A}$ ( $\mathrm{A} 1$ and $\mathrm{A} 2)$, B (B1, B2, B3, B4 and B5) and C (C1 and C2).

The morphological and morphometric characteristics allow suggestions for the surgical therapy, as the patients from group A have a greater chance of definitive treatment, those of group B of palliative treatment and those of group C of definitive palliative treatment.

The mortality presented a greater correlation with the morphologic characteristics than with the morphometric characteristics.

\section{BIBLIOGRAPHIC REFERENCES}

1. Tchervenkov CI, Roy N - Congenital Heart Surgery Nomenclature and Database Project: pulmonary atresia ventricular septal defect. Ann Thorac Surg 2000; 69:S97-105.

2. Haworth SG, Macartney FJ - Growth and development of pulmonary circulation in pulmonary atresia with ventricular septal defect and major aortopulmonary collateral arteries. $\mathrm{Br}$ Heart J 1980; 44:14-24.

3. Castañeda AR, Jonas RA, Mayer JE, Hanley FL - Tetralogy of Fallot. In: Castañeda AR, Jonas RA, Mayer JE, Hanley FL, eds. Cardiac surgery of the neonate and infant. 1.ed. Philadelphia, WB Saunders, 1994; 215-34.

4. Marcial MB, Jatene AD - Surgical management of the anomalies of the pulmonary arteries in the tetralogy of Fallot with pulmonary atresia. Semin Thorac Cardiovasc Surg 1990; 2:93-107.

5. Croti UA, Marcial MB, Jatene MB, Riso AA, Tanamati C, Aiello VD, Dallan LA, Oliveira AS - Classificação anatômica e correção cirúrgica da atresia pulmonar com comunicação interventricular. Rev Bras Cir Cardiovasc 2001; 16:321-36.

6. Nakata S, Imai Y, Takanashi Y, Kurosawa H, Tezuka K, Nakazawa M, Ando M, Takao A - A new method for the quantitative standardization of cross-sectional areas of the pulmonary arteries in congenital heart diseases with decreased pulmonary blood flow. J Thorac Cardiovasc Surg 1984; 88:610-9.

7. Reddy VM, Petrossian E, Mcelhinney DB, Moore P, Teitel DF, Hanley FL - One-stage complete unifocalization in infants: When should the ventricular septal defect be closed? J Thorac Cardiovasc Surg 1997; 113:858-68.

8. Croti UA, Marcial MB, Oliveira AS - Atresia pulmonar com comunicação interventricular. Arq Bras Cardiol 2002; 78:521-23 
9. Behrman RE, Kliegman RM, Arvin AM, Nelson WE Laboratory medicine and reference tables. In: Behrman RE, Kliegman RM, Arvin AM, Nelson WE - Eds. Textbook of pediatrics. 15.ed. Philadelphia, WB Saunders 1996; 2079.

10. Sawatari K, Imai Y, Kurosawa H, Isomatsu Y, Momma K Staged operation for pulmonary atresia and ventricular septal defect with major aortopulmonary collateral arteries: new technique for complete unifocalization. J Thorac Cardiovasc Surg 1989; 98:738-50.

11. Puga FJ, Leoni FE, Julsrud PR, Mair DD - Complete repair of pulmonary atresia, ventricular septal defect, and severe peripheral arborization abnormalities of the central pulmonary arteries: experience with preliminary unifocalization procedures in 38 patients. J Thorac Cardiovasc Surg 1989; 98:1018-29.
12. Carotti A, Di Donato RM, Squitieri C, Guccione P, Catena G - Total repair of pulmonary atresia with ventricular septal defect and major aortopulmonary collaterals: an integrated approach. J Thorac Cardiovasc Surg 1998; 116:914-23.

13. Kirklin JW, Barratt-Boyes BG - Ventricular septal defect and pulmonary stenosis or atresia. In: Kirklin JW, Barratt-Boyes BG, eds. Cardiac Surgery. 2.ed. New York, ChurchillLivingstone, 1993; 861-1012.

14. Macé L, Dervanian P, Losay J, Folliguet TA, Santoro F, Abdelmoulah S, Argiriou M, Verrier JF, Neveux JY - Défauts d'arborisation pulmonaire des formes complexes d'atrésie pulmonaire à septum ouvert: unification, unifocalisation et réparation complète. Arch Mal Coeur 1996; 89:561-8. 